\title{
A Critical analysis on how testimony psychology influences criminal investigations in Brazil
}

\begin{abstract}
This paper discusses different perspectives in psychology in contact with criminology and the operation of the criminal justice system. It is dedicated to think how the testimony psychology integrates the field of Criminology in Brazil and the relationship of psychological knowledge with the Criminal Justice System in Brazil, trying to emphasize fundamental principles of Brazilian law and ethical implications in the practice of psychology.
\end{abstract}

Keywords: brazilian psychology,brazilian criminology, history of psychology, forensic psychology history

\author{
Volume 4 Issue I - 2017 \\ Juliana Ferreira da Silva,' Valerio Lousada de \\ Carvalho ${ }^{2}$ \\ 'Department of Psychology, Federal University of Rio de Janeiro, \\ Brazil \\ ${ }^{2}$ Euro American University Center, Brazil
}

\begin{abstract}
Correspondence: JulinaFerreria da Silva, Department of Psychology, Federal University of Rio de Janeriro, Brazil, Tel 55 6I 98I530290,Email jumeil@hotmail.com
\end{abstract}

Received: September 24, 2016 | Published: January 10, 2017

\section{Introduction}

This paper discusses different perspectives in psychology in contact with criminology and the criminal justice system. It is dedicated to think how the testimony psychology integrates the field of Criminology in Brazil and discuss their effects in regards of Brazilian law. For the historiography of psychology in Europe, there is considerable discussion about the trajectory of the constitution of the psychology of testimony. On that continent, such studies begin in the early twentieth century, with Binetin France and Stern in Germany. In the United States of America, much of contemporary research in testimony psychology deals with the efficacy of eyewitnesses, i.e., their ability to:

\section{i. Correctly perceive the situation}

ii. Store the perceived information, and

iii. Tell accurately what they witnessed ${ }^{2}$

Already on the development of this field in Brazil, there is very little systematized knowledge. In November 2014, there is news of an unusual procedure conducted by the RibeirãoPreto police station in the state of São Paulo, Brazil. This is the preparation of a report issued by analysts of the Paulista Institute of Bioethical and Legal Studies (IPEBJ), a private company of expert services regarding the testimony of a man questioned on suspicion of murder. We propose to analyze the report, while event - in the sense given by Michel Foucault ${ }^{3,4}$ - and think about it from a critical point of view. We will take the use of this document during the police investigation as analyzer of the relationship of psychological knowledge with the operation of Criminal Justice in Brazil, trying to emphasize fundamental principles of Brazilian law and ethical implications in the practice of psychology. According to the report, some suspicious behaviors are indicative of anger and anxiety and can point to the suspect's guilt in the crime of murder. Movements of the shoulder and torso, as well as change on nose color could be taken, therefore, as evidence that the suspect is trying to trick the investigator and tries to hide his authorship in the murder. "Highlights the passage in which the target says, 'that boy was everything to me'. The analysis of nonverbal behavior indicates point of incongruity between speech and emotion. Actions units 4.9.23 expressed during the elocution are compatible with the emotion of anger "IPEBJ. - FSI Brazil - Forensic Science Investigation Figure 1. We believe that some discussions that pervade the history of Brazilian criminology are important to think about the events of that murder investigation and may also bring important elements to the discussion of legal and ethical aspects of such an action under the Brazilian criminal justice system. In previous work, one of the authors of this article proposes a reflection on the history of the testimony of psychology in Brazil through the use of the past as a way to understand certain devices of power-knowledge of the present. ${ }^{5}$ In this work, we follow a similar direction, seeking to bring some reflections from the past to discuss practices in nowadays. The first of these discussions is related to an analysis of an important Brazilian police investigation manual, published in 1956.

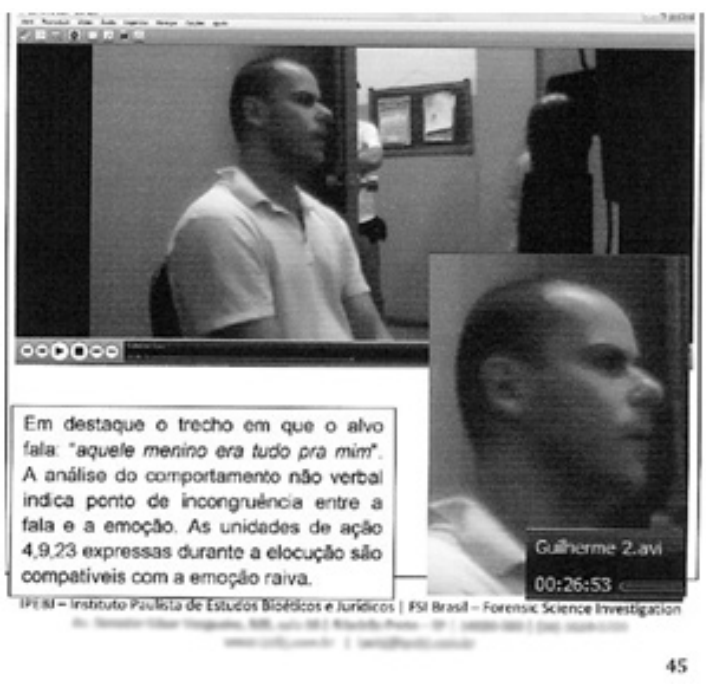

Figure I Civil Police of São Paulo - Portal GI. 


\section{The handbook of police investigation}

In 1956, an important manual of police investigation is published by a Police Chief of São Paulo State Police, Coriolano Nogueira Cobra. The "Handbook of Police Investigatio N" becomes fundamental source in the formation of Brazilian police investigators, taking part of the bibliography of several police academies in the country. Currently, the manual is in its sixth edition revised and updated, dated $1983 .{ }^{6}$ This book devotes four chapters to obtain information through witnesses, victims and defendants. The chapters dedicated to the interrogation of the suspects deserve special interest. Throughout the chapter the author makes a point of emphasizing that the goal of the investigator should be forcibly get the confession, even through artifices. In a passage in particular, the author states that psychology is one of the strategies to confront the subject to obtain confession: "When the police officer who interrogates the suspect is convinced that the man who denies is really guilty or that the evidence against him is strong, and the means to convince him to confess fail to have results, the policeman will have to insist, trying to force a confession. The policeman can and should then seek to achieve the goal, with argument or making use of artifices or stratagems. To argue, the one who interrogates can take advantage of information provided by the suspect and others, known and obtained from other sources in the investigation. The investigator may tell the suspect that his behavior and his psychological manifestations, which will be listed, show that he is lying. The policeman will claim the futility of denying, in view of other elements already collected, and will point the lies told by the suspect". 6

In the chapter dedicated to the recognition and search for sincerity, Cobra ${ }^{6}$ describes the methods of that the Civil Police of the State of São Paulo has to ascertain the sincerity of the suspects during the investigation. The author describes the test methods used in Anthropology Laboratory of the Investigation Department. It is important to emphasize that these methods are operated by experts, who act as collaborators in the investigation. "Verification of sincerity that we will talk about is the work that aims to find out if the person lies or don't on providing information. Always has been and always will be a concern in the activity to prosecute and punish the perpetrators of anti-social acts check when the people involved in them or able to enlighten them tell the truth or not. Lately, verification of sincerity already has interesting methods and remains the subject of numerous experiments and field studies increasingly competitive. Who studies police investigation, although will not apply any of the existing methods, because these must be carried out by experts, should obtaining good notions on the matter, at least to know the possibilities of the sincerity verification as a means to assist the investigation. Various methods are in use. They are, however, the best known and used: Jung-Bleuler Proof, the Psychogalvanic Reflex Proof, the Benussi Proof and the Lie Detector". ${ }^{6}$ It is necessary to think about the use that is made of specialized expert in the truth verification method. As a specialized knowledge, such testing methods overlies the investigation with the prestige of a scientific knowledge and give to the power to punish the justification that is needed for its operation. We work with the important contribution of Michel Foucault, ${ }^{3}$ related to the operating modes of the regime of truth in the exam. But what we want to show is a different regime of truth, which does not deal with the future virtuality of the subject, but with the establishment of a truth about his past. The question of testimony psychology does not deal with what the subject will do in the future, but what he did, his guilt in the crime, whether it is right past that he claims to have, about the truth of what he refuses to tell. This is a fundamental difference between these regimes of truth and, therefore, on the effects that this knowledge-power of testimony psychology can engender, while criminalization device.

"It is therefore a discursive regime that is based on the name of truth and justice, but about which we can only ensure that produces subtle and powerful culpability. A power-knowledge that runs through the operation of criminal justice, determining suspicions, leading to inquisitorial prosecutions and convictions. Finally, a psychology whose conceptual basis and practical applications must be historically analyzed, contextualized and criticized, and thus may be more frankly thought their political and pragmatic effects" ${ }^{5}$ In this topic, we need to think about which power-knowledge devices are operating in contemporary psychology speech. Therefore, we propose the contrast between the theories of Paul Ekman ${ }^{7,8}$ and Kassin. ${ }^{9}$ Although the test methods are different, we perceive some similarities between the testimony psychology as is presented in Cobra and contemporary psychology by Paul Ekman. ${ }^{7}$ Currently, Ekman is one of the main reference authors in the psychological study of the behavioral signs of lying. Ekman's research related to lie in the criminal context dating from about 1985, but his complete work began with the study of facial signs of emotion in the late 1950. The author is proud to have gathered more than ten thousand facial expressions and identified those that would be central to the emotions gathered in the face of the atlas, "a systematic description in words, pictures and movies of how to measure facial movement in anatomical terms". ${ }^{8}$ In 1978, his research team publishes Facial Action Coding System - FACS, a tool used to measure the face by facial micro expressions. This system allowed the author an application of their research to the US criminal justice system. In 1985, he published the book "Telling Lies Clues to Deceit in the Marketplace, Politics, and Marriage", 7 the result of partnership with government institutions of public safety and criminal justice, such as the FBI, CIA and ATF. "By using the Facial Action Coding System, we identified the facial signs denouncing the lie. What have called micro expressions - very fast facial movements, lasting less than a fifth of a second - it is an important source of leakage, revealing an emotion that the person is trying to hide. A false expression can be reported in several ways: in general is slightly asymmetrical and lacks uniformity so that flows from time to time face". ${ }^{9}$ First, Ekman ${ }^{7}$ defines what a lie is, distinguishing it from other forms of untruths: delirium, misnomer. The central point of its definition focuses on the choice that is present only in the lie. The liar can choose not lie, but lies. Fooling the other is its deliberate and capable option.

"A liar can choose not to lie. Misleading the victim is deliberate; the liar intends to misinform the victim. The liese may or may not be justified, in the opinion of the liar or the community. The liar may be a good or a bad person, liked or disliked. But the person who lies could choose to lie or to be truthful, and knows the difference between the two". ${ }^{7}$ The definition of Ekman therefore presupposes a subject capable in the approximate direction to legal: one who understands what is true and false, and is able to control his conduct as such a notion. In addition to this, the author adds another specification. The lie, to be considered as such, should aim to believe that is true. "It is not just the liar that must be considered in defining a lie but the liar's target as well. In a lie the target has not asked to be misled, nor has the liar given any prior notification of an intention to do so". ${ }^{7}$ The author distinguishes two ways to lie: conceal and falsify. While concealing the liar hide some information, saying something that is not strictly true. Already the falsify, a liar would make a step further: in addition to conceal the truth, presents false information as true. In comparison, the author considers that the deception is more 
used by liars. The reason was the ease that gives the liar not need to invent anything, besides not having the possibility of contradiction in advance of the story being told by him. The deception would be less socially reprimanded, often even considered a condescension liar not to confront the listener with an unpleasant truth. If caught, it would be even easier to invent a liar viable excuse: memory failure, ignorance, intended to reveal the information later on. Based on this, the author analyzes the use of the phrase "to the best of my recollection" the person's testimony on oath, then watching a way of preparing the ground for a possible concealment of discovery. Say not remember what really remember was the intermediary between concealment and falsification. The concealment and falsification also refer to emotions, not just information. The lie also be to try to fake an emotion that feels or mislead about the cause of an emotion. Another way of lying would tell the truth ironically, with mocking tone and ridicule of expression, so that the person does not believe what is being counted. The author believes that positive emotions are easier to falsify with smile mask. More complicated would be negative emotions, whose facial expression is more difficult to fake. For, ${ }^{7}$ the main signs of lying are obtained from hot spots. These indications would not endorse the lie itself, but point to the need for more research. They can be found in the following human productions:

1. Words - careless mistakes, exchanged words, circumlocution or indirect speech

\section{Voice - pause, hesitation}

3. Body - Nonverbal emblematic movement, decrease in the illustration

4. Autonomic nervous system - breathing, often swallowing, increased sweating

"I have described behavioral clues that may leak concealed information, indicate that the person has not prepared his line, or betray an emotion that does not fit the line being taken. Slips of the tongue, emblematic slips, and tirades can leak concealed information of any kind-emotions, past deeds, plans, intentions, fantasies, ideas, etc. Indirect speech, pauses, speech errors, and a decrease in illustrators may indicate that the speaker is being very careful about what is said, not having prepared the line being taken. They are signs of any negative emotion. A decrease in illustrators also occurs with boredom. Raised voice pitch and louder, faster speech occur with fear, anger, and perhaps excitement. The voice changes in the opposite way with sadness and perhaps with guilt. Changes in breathing or sweating, increased swallowing, and a very dry mouth are signs of strong emotions, and it may be possible in the future to determine which emotion from the pattern of these changes". ${ }^{7}$

Besides these, facial expressions may expose the falsity of several ways:

\section{The asymmetry of the face}

2. No involuntary movements, and

\section{Timing of expression}

The similarity that we have established here is based on the construction similar device in which the operators of psychological knowledge unveil the truth by signs, such as pauses, delays, stammers, smiles, tremors, among others. In both perspectives, there is assumption that the immediate is true - the truth comes first. ${ }^{5}$ Analyzing the postulates of Ekman, you can say that his work adopts the basic proposition that "the truth comes first": the emotion has a facial immediate correlative. The first expression is true. If another put in its place - even for just millionths of a second interval - this other expression that comes second is the liar, it is like a mask that overlaps the original and true expression. Hence also concludes that for Ekman, "emotion is univocal" - the face should be expressive coherence. If there is a mixture of emotional movements in the face, this is a sign of hypocrisy. This psychological discourse is coated values based on the superiority of scientific knowledge, which proclaims able to identify the most noticeable signs, seemingly insignificant details, but that may reveal deep range of phenomena. From this point of view, we would like to discuss the critical view proposed by Carlo Ginzburg from the concept of evidential paradigm..$^{10}$ This concept is very interesting for demonstrating an ongoing device in the epistemological model within the humanities used to develop forms of social control. In the case of witness psychology, this semiotic model uncovers signs, comes to lie or fake and finally criminalizes the subjects who issued them. Such evidentiary model operates in the world of police investigations. So we can now think contemporary research of Kassin, ${ }^{9}$ notably the intelligibility that the author gives the modus operandi of the police detectives. To remind, Kassin 9 presents three types of false confessions (voluntary and coerced compliant involuntary and involuntary internalized). With regard to involuntary confessions, Kassin explained that they are produced by own criminal justice system through enforcement action or coercion of police officers. Now why would the cops do so much effort to extract an involuntary confession of a suspect? Why bluffing, both corner and coerce someone to confess the authorship of the crime? Kassin explains that detectives "elect" certain suspects on which the interrogation tactics mentioned above are conducted. Before the actual questioning, that led the police station in setting specifically set up for this, there is another procedure called interview, which is conducted by detectives in common public space. Reid Manual, more important and publicized manual US police investigation, detectives teaches some behavioral signs so that they detect whether respondents lie. They are verbal and non-verbal, attitudes and behaviors that indicate a lie. Thus, if an interviewee avoids looking at the detective eyes, or express fear, anxiety or stress when approached by the police, this impression is taught by detectives as fault indication and as a consequence this staff is chosen by the police for interrogation conducted with tactics coercion and suggestibility on the authorship of the crime. From the perspective of [9], three processes are responsible for the existence and the consequences of false confessions in the criminal justice system. First, the officers elected innocent people as targets of his interrogation by making wrong judgment about the possibility of detecting the truth or lie in the speech of suspects. Second, innocent people sometimes confess crimes they did not commit because of certain interrogation tactics, vulnerabilities suspicion devices and the exaggerated belief in justice itself. Third, the judges fail to even disregard the confessions that they know have been forged by coercion.

A critical view such as Kassin's it is important to present a new form of psychology of performance within the criminology. The intelligibility that Kassin gives the false confessions phenomenon is totally different to what makes Paul Ekman. Kassin unveils a series of interrogation tactics - such as incommunicability of the questioned promoted by setting the bluff with false criminal evidence - that are grounded in a speech unveiling the truth and who are, otherwise, producing false confessions. Thus, Kassin psychology, instead of contributing to the criminalization process, discusses the influence the testimony psychology has in the practice of criminal justice operators (detectives, judges) and the production of guilt by the lie unveiling. 


\section{What Brazilian law says}

In this exacerbated search for the conviction of guilt of the suspect, there is the confrontation with the need to contradict the evidence and assumptions on the part of the accused. The constitutional provision stipulated in art. 5, item LV "to litigants in court or administrative proceedings and defendants in general are ensured of the contradictory and full defense, with the means and resources inherent to it", it is to be respected in police investigations. They must give full access to defense documents produced. The actions taken by the authorities should be subject to opposing interpretations should be seen and contradicted even if perchance it be placed under review in the court stage. The police investigation is not a merely illustrative, as little dispensable for the formation of the suspect's guilt. The inquiry has the power to convince not only the holder of the prosecution (prosecution) as to interfere with the conviction of the jury. A good example of the importance and power of persuasion of the police investigation is the principle that takes on the maintenance of the prison in the act and the application of probation, both purely justifiable in view of the information gathered in the inquisitorial stage. In this context, ensuring the need for a defense on an equal position with the prosecution, we cannot fail to protect a right "unavailable and inalienable" provided for in the Constitution of a country. The right to contradictory it is not only to provide one more weapon to individual defend than the state or a private accuses him involves something much bigger, it is to do justice, to give legitimate conditions in the search for the real truth, justice to be, committed so that the applicators, the accused and society in particular do not be in doubt when the real need that law enforcement and the avoidance distrust the accused that his trial was fair. The large defense has a big reach in the Brazilian legal system that generates so many rights to the accused, including the right to contraditory, which allows the accused even lie in court, which many contend with the need to search for the real truth. We found this possibility in several texts of national law but expressed mainly in art. 5, item LXIII of the Federal Constitution, generating not only the right to remain silent, but the right of being uncooperative, the right to do not self-incriminate and therefore the right to do not speak the truth.

\section{To think about}

Years of ethics and critical thinking on one side and on the other, the construction of subtle methods of social control and criminalization of subjects. It is in this context of interests, catch and demands that psychology mixes with Criminology in Brazil. We are confident that a deep discussion of the conceptual foundations and practical effects of such an action in the criminal justice system can move forensic psychology from that so complicated place. Psychology is part of the transdisciplinary knowledge of criminology, that's right. But the way it integrates can - and should - be changed. Psychology is much more interesting when it serves to problematize the operating logic and current devices in criminology.

\section{Acknowledgments}

None.

\section{Conflicts of interest}

None.

\section{References}

1. Sporer SL. A brief history of the psychology of testimony. Current Psychological Reviews. 1982;2(3):323-339.

2. Aronson E, Wilson TD, Akert RM. Social psychology (8th edn). Old Tappan, Pearson, UK, 2012; pp. 1-576.

3. Foucault M. A verdade e as formas jurídicas ( $3^{\text {rd }}$ edn). NAU, USA, 1975a; p. $1-79$.

4. Foucault M. Surveiller et punir, naissance de la prison. Gallimard, France, 1975b;pp. 1-313.

5. Silva J. Everything you say... And do not say...: Essay on the History of Psychology of Testimony on Brazilian Criminology. International Journal of Criminology and Sociological Theory. 2015;8(1):1-12.

6. Cobra CN. Manual de Investigação Policial São Paulo. Saraiva, UK. 1983.

7. Ekman P. Telling Lies Clues to Deceit in the Marketplace, Politics, and Marriage. WW-Norton \& Company, USA, 1985; pp. 1-368.

8. Ekman P. Emotions Revealed, Recognizing Faces and Feelings to Improve Communication and Emotional Life. Henry Holtand Company, USA, 2003; pp. 1-285.

9. Kassin SM. False confessions causes, consequences, and implications for reform. Current Directions in Psychological Science. 2008;17(4): 249-253.

10. Ginzburg C. Clues: Roots of a Scientific Paradigm. Theory and Society. 1979;7(3):273-288. 